\title{
ДИСКУССИИ
}

\section{Стейкхолдерский подход к управлению, ориентированному на приращение стоимости компании}

\author{
Ивашковская И.В. ${ }^{4}$
}

В статье обоснована оригинальная модель интегрированного управления стоимостью компании, отвечающая принципам создания стоимости для стратегических финансовых и нефинансовых стейкхолдеров компании. Обосновано, что для приращения стоимости для стейкхолдеров необходимо следовать принщипу потока положительной экономической прибыли для нефинансовых стейкхолдеров компании. Показано, что интегрированный подход требует на уровне менеджмента внедрения модели управления на основе стоимости для стейкхолдеров компании (stakeholder value based management, STVM), на уровне совета директоров - модели корпоративного управления на основе стоимости для стейкхолдеров (stakeholder's value based corporate governance, STVG). Для мониторинга процесса создания стоимости для стейкхолдеров необходима третья составляющая - стратегические отчеты о стоимости компании.

$$
\text { JEL: G32, G38 }
$$

Ключевые слова: стейкхолдерский подход, экономическая прибыль, стоимость компании, советы директоров

В условиях перехода к инновационной экономике формируется новый системный контур нефинансовых форм капитала и на этой основе - новый подход к финансовому анализу компании. Особенности его становления рассмотрены автором в предыдущих работах (Ивашковская, 2007; Ивашковская, 2008в; Ивашковская, 2011).Растущая роль системного контура нефинансовых форм капитала для успеха в конкуренции, а следовательно, и для построения обоснований управленческих решений предполагает и новые подходы к выбору стратегических альтернатив компании. Необходимо достижение гармонизации интересов стратегических нефинансовых стейкхолдеров как условие снижения стейкхолдерского риска компании или риска утраты ценности интеллектуального и социального капиталов для компании. Стратегические решения должны соответствовать новым принципам стоимостного мышления - созданию приращения стоимости для стейкхолдеров компании (stakeholder value added, STVA).

\section{Добавленная стоимость для стейкхолдеров (STVA) как поток экономической прибыли}

Создание стоимости для стейкхолдеров (STV) необходимо увязывать с принципом экономической прибыли. Представляя ее в виде спреда доходности, мы получаем разность явной ставки доходности и неявной (альтернативной) требуемой ставки доходности на вложенный с данным риском капитал. Применительно к нефинансовым стейкхолдерам критерий экономической прибыли также опирается на принцип эффективной реализации ими своих интересов в виде получаемых выгод по сравнению с альтернативными издержками. Как носители материальных ресурсов, интеллектуального и социального

\footnotetext{
${ }^{4}$ Д-р эконом. наук, ординарный профессор, зав. кафедрой экономики и финансов фирмы, зав. лабораторией корпоративных финансов НИУ ВШЭ.
} 
капиталов, они претендуют на получение от конкретной компании вознаграждения за них, компенсирующего их собственные альтернативные издержки, которые вытекают из их рыночных возможностей. Нефинансовые стейкхолдеры, как и финансовые, рассчитывают на получение экономической прибыли не ниже нуля. Она может быть рассмотрена в форме положительного спреда ставок (в процентном выражении) или положительной разности (в абсолютном выражении) между полученной ими выгодой и требуемой ими (альтернативной) величиной.

К анализу процесса создания экономических прибылей для стейкхолдеров применим подход создания в компании рент и квазирент, представленный П. Милгромом и Д. Робертсом (Milgrom, Roberts, 1992), а также анализ рент в отношениях менеджмента и стейкхолдеров (Charreaux, Desbrieres, 2001; Castanias, Helfat, 1991). Экономические прибыли для нефинансовых стейкхолдеров могут возникать в разных звеньях цепочки ценности компании, например:

- на входе в виде разности между ценами, полученными поставщиками за ресурс, и их альтернативными издержками, формирующими оценку их ресурса;

- в процессе создания продукта в виде разности между зарплатой персонала и менеджмента и их альтернативными издержками, формирующими оценку их ресурса;

- в процессе продвижения продукта к клиентам в виде разности цен в соответствии с заключенными явными контрактами и альтернативными издержками, формирующими оценку их ресурса.

Стоимость для стейкхолдеров (STV), созданная за данный период, в конечном счете представляет разность альтернативных издержек клиента (конечное звено цепочки ценности, создаваемой в компании) и суммы альтернативных издержек остальных стейкхолдеров, участвовавших в создании и продвижении продукта (начальное и срединные звенья цепочки ценности в компании). Альтернативные издержки стейкхолдеров можно определять двумя способами. Первый из них основывается на конкурентных ценах. Сопоставление осуществляется с рыночными ценами, которые может получить тот или иной стейкхолдер за свой ресурс и в которых уже учтены дополнительные издержки входа (entry cost) в коммуникации $\mathrm{c}$ компанией. Второй способ определения альтернативных издержек учитывает издержки выхода из коммуникаций с компанией (exit cost). Издержки выхода зависят от условий использования ресурсов, которые создает компания, способствующих, например, в случае персонала наращиванию мастерства и специфических знаний. Такие издержки выхода ведут к снижению альтернативных издержек стейкхолдера.

С точки зрения нефинансового стейкхолдера фактическая компенсация может быть прямой и немедленной в виде определенных выплат в сравнении с имеющимися на рынке альтернативами. Выгоды также могут быть отложенными на некоторое время и косвенными. Так, например, в случае персонала, соглашающегося на выполнение работы за оплату, которая на момент заключения контракта с компанией ниже альтернативных издержек на рынке труда, но позволяет войти в компанию, в которой стейкхолдер имеет благоприятную возможность достаточно быстро нарастить собственную квалификацию и тем самым получить возможность увеличить в будущем оценку своего ресурса. В случае с клиентами компании выгоды могут охватывать как непосредственные последствия заключаемой сделки (соотношение цены и качества продукции, например), так и те результаты, которые данная сделка может принести для цепочки последующих сделок (скорость поиска, накопление опыта и переговорной силы, даже влияние на цены следующих сделок).

Таким образом, критерий экономической прибыли на теоретическом уровне определяет создание результата, ожидаемого всеми категориями стейкхолдеров - финансовыми и нефинансовыми, и является единым для всех. Применение этого критерия помогает выделять разные ситуации создания стоимости для стейкхолдеров компании. Во-первых, ситуации создания положительной экономической прибыли для всех групп финансовых и нефинансовых стратегических стейкхолдеров:

$$
\Delta S H V>0, \Delta S T V A_{N O N-F I N}>0,
$$


где:

SHV - shareholder value - стоимость акционерного капитала;

$S T V A_{N O N-F I N}-$ stakeholder value non-financial - стоимость для нефинансовых стейкхолдеров.

Во-вторых, ситуации, которые ведут к созданию положительной экономической прибыли для акционеров, но экономическая прибыль для стратегических нефинансовых стейкхолдеров при этом достигает отрицательных значений. Создания стоимости для нефинансовых стейкхолдеров не происходит, и соответственно: $\Delta S H V>0$, $\Delta S T V A_{N O N-F I N}<0$. В-третьих, ситуации, в которых экономическая прибыль не создается для финансовых стейкхолдеров, но создается для некоторых категорий стратегических нефинансовых стейкхолдеров: $\Delta S H V<0, \Delta S T V A_{N O N-F I N}>0$. Наконец, ситуации, в которых экономическая прибыль не создается вообще.

Попадая в ситуацию разрушения стоимости, нефинансовые стейкхолдеры, так же как и финансовые, теряют мотив продолжения участия в коммуникациях с компанией или могут выйти из таких коммуникаций. Решение о таком выходе зависит от издержек выхода, которые специфичны для конкретной категории стейкхолдеров. Необходимо отметить, что на решение о выходе стейкхолдера из коммуникаций с данной компанией влияет группа факторов. Прежде всего они зависят от возможности принятия менеджментом решений о величине ренты, накапливаемой в компании, составляющей ресурс управленческой гибкости (managerial slack) (Castanias, Helfat, 1991; Castanias, Helfat, 2001). Частично она может быть увязана с задачами инвестиций и поддержания достаточности ликвидных средств. Вовторых, принятие стейкхолдером решения о выходе может быть обусловлено невозможностью использовать сложившуюся неблагоприятную ситуацию в собственных интересах в будущем и получить отложенную дополнительную компенсацию после завершения некоего периода разрушения стоимости для данной категории стейкхолдеров. Втретьих, важную роль играет сила влияния этой категории стратегических стейкхолдеров или данного конкретного стейкхолдера на ситуацию в компании, которая, как показано выше, связана с ресурсным критерием выделения стейкхолдеров как «коллективных действующих лиц», с критериями риска, а также издержками выхода. В-четвертых, нельзя не учитывать и состояния рынков тех ресурсов, где формируются альтернативные издержки разных категорий стратегических стейкхолдеров. Оно определяет для них не только оценки альтернатив, но и возможность их реализации в результате разрыва коммуникаций с компанией, в которой экономическая прибыль для них отрицательна. Наличие данных факторов означает, что со стороны компании могут быть приняты меры для повышения издержек выхода для определенных категорий стейкхолдеров.

Подход к стоимости для всех стейкхолдеров с позиций потоков экономической прибыли позволяет создать концептуальный формат анализа, способствующий продвижению в инструментальном плане - к разработке систем показателей и других инструментов выражения STVA, который рассматривается в следующих главах.

Принцип стоимости для всех стейкхолдеров (STVA) предполагает выполнение условия достижения сбалансированной архитектуры капитала. Такая постановка проблемы означает необходимость оценивания комбинации, с одной стороны, специфических инвестиций, представленных в интеллектуальном и социальном капиталах, и с другой - традиционных инвестиций в форме финансового капитала, не являющегося специфической, не воспроизводимой инвестицией, необходимой для достижения устойчивости бизнеса. В рамках данной комбинации не может быть приоритета финансового капитала в смысле создания конкурентных преимуществ. А это означает, что ситуации, в которых достижение положительной экономической прибыли для нефинансовых стратегических стейкхолдеров может требовать решений, при которых экономическая прибыль для финансовых стейкхолдеров не только не увеличится, но и может снижаться на краткосрочном горизонте. Принцип «неразрушения потока экономической прибыли» должен быть распространен на 
нефинансовых стратегических стейкхолдеров. Поэтому, как показано выше, учет интересов нефинансовых стейкхолдеров предполагает работу с негативными и позитивными экстерналиями до принятия решений. Нарушение баланса ведет к нарастанию стейкхолдерского риска, что в свою очередь вызывает рост затрат на совокупный финансовый капитал и снижение экономической прибыли акционеров.

Рассмотренные автором характеристики гармоничной компании (Ивашковская, 2011) позволяют сформулировать задачу создания новой модели управления, ориентированного на создание стоимости. С этой целью необходима система управления стоимостью компании, в которой интегрированы интересы финансовых и стратегических нефинансовых стейкхолдеров.

\section{Принципы интеграции контура финансовых и нефинансовых стейкхолдеров в управлении компанией}

Новая концепция управления стоимостью компании должна охватывать системный контур нефинансовых форм капитала, фокусироваться на объемном пучке интересов финансовых и нефинансовых стейкхолдеров фирмы и предполагает иные принципы балансирования в нем. Элементы такой системы показаны на рисунке 1.

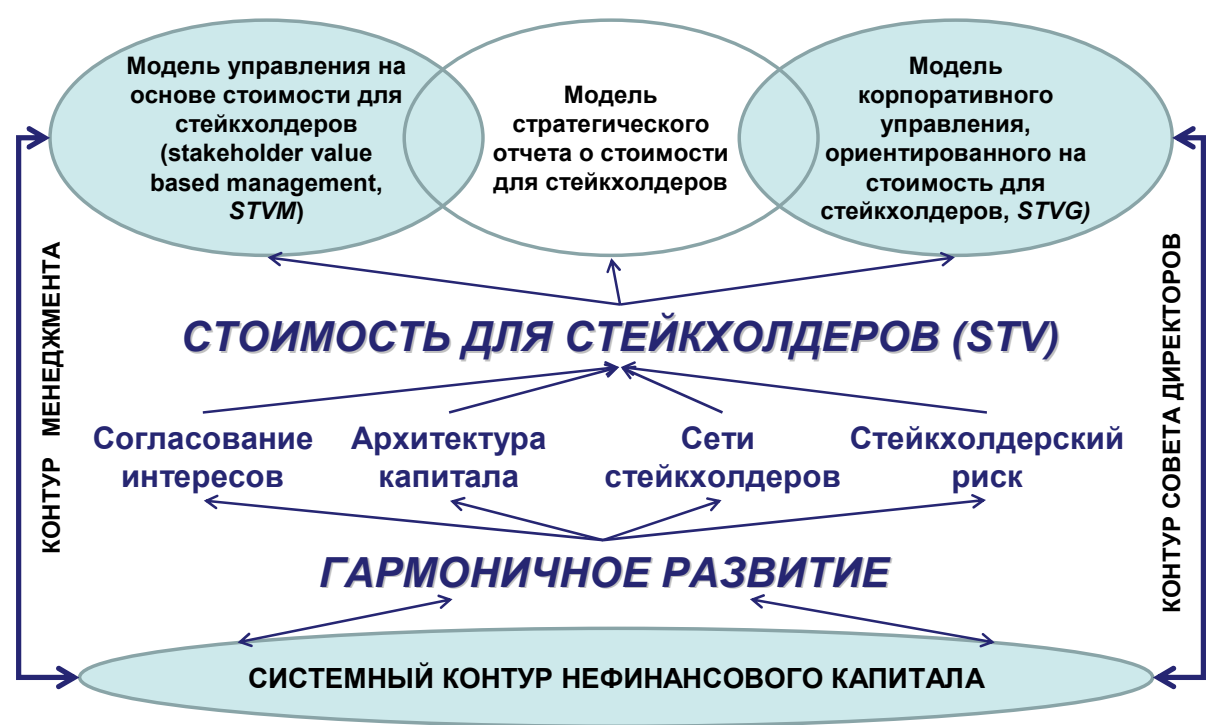

Рисунок 1. Система интегрированного управления стоимостью компании

Гармонизация, достигаемая в пространстве интересов стратегических стейкхолдеров, не тождественна нахождению баланса интересов агента и принципала, в роли которого выступают финансовые стейкхолдеры. Гармоничная компания предполагает обеспечение согласования интересов финансовых и нефинансовых стейкхолдеров, формирующихся в пространстве взаимодействия трех форм капиталов - финансового, интеллектуального и социального, - и согласования краткосрочных и долгосрочных горизонтов их реализации. Формирование нового типа структуры капитала - архитектуры капитала - фиксирует важнейшую особенность гармоничной компании. Архитектура капитала образует новый срез анализа фирмы, предполагает новое стоимостное мышление и изменения в подходах к корпоративному управлению как механизму решения задачи гармонизации интересов стейкхолдеров. Задача построения сбалансированной архитектуры капитала основывается на принципе неразрушения потока экономической прибыли, который должен быть распространен и на нефинансовых стейкхолдеров.

Гармонизация интересов позволяет достичь особой конфигурации факторов стоимости, в которой выделяется фактор стратегического уровня в форме сетевых взаимодействий стейкхолдеров (Ивашковская, 2011). Такие сети создают дополнительный механизм 
накопления интеллектуального и социального капиталов и становятся факторами создания стоимости более высокого порядка, обладающей мощным воздействием на выбор стратегических альтернатив и эффективность исполнения ее корпоративной стратегии. Отсутствие гармонизации интересов ведет к возникновению особой группы факторов инвестиционного риска - стейкхолдерского риска. Гармонизация интересов направлена на создание приращения стоимости для всех стейкхолдеров (STVA), в основе которого лежит критерий экономической прибыли. Попадая в ситуацию отрицательной экономической прибыли, нефинансовые стейкхолдеры теряют мотив продолжения участия в трансакциях с компанией и могут выйти из них. Решение о таком выходе зависит от издержек выхода, которые специфичны для конкретной группы стратегических стейкхолдеров.

Для внедрения данных принципов в деятельность менеджмента необходим первый существенный элемент системы интегрированного управления стоимостью - модель управления на основе стоимости для стейкхолдеров компании (stakeholder value based management, STVM). Модель STVM рассматривается как совокупность процессов координации в компании и соответствующих им инструментов, нацеленных на достижение положительного приращения стоимости для стейкхолдеров (stakeholder value added, STVA). Основные характеристики этой модели (STVM) обобщены на рисунке 2 (Ивашковская, 2009, c. 151).

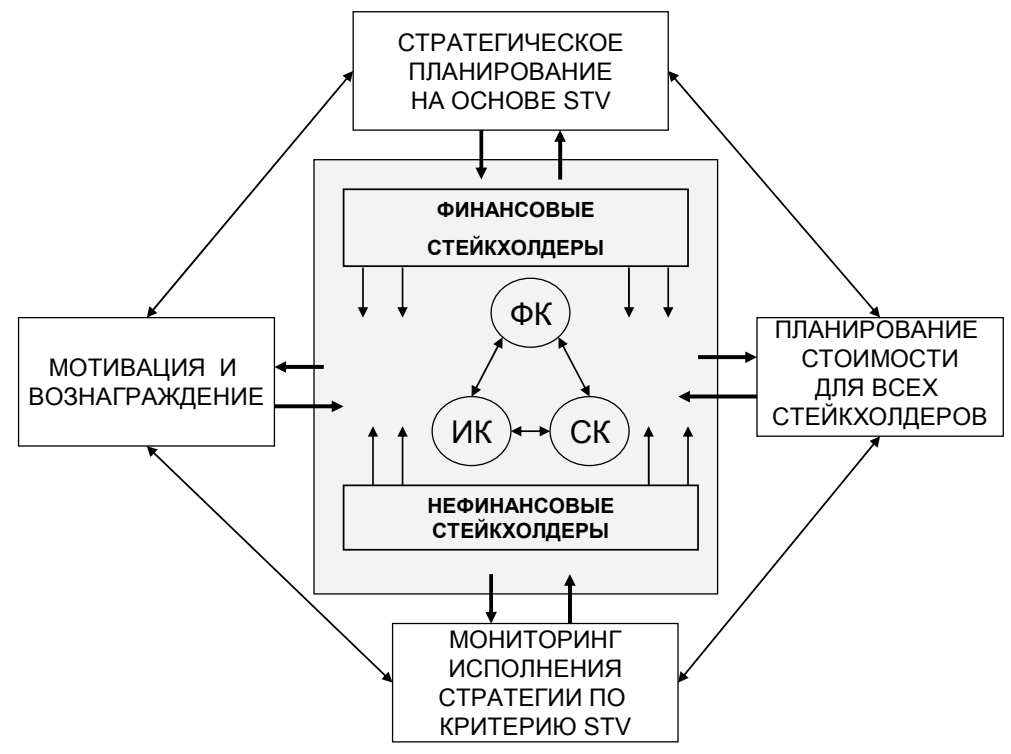

Рисунок 2. Модель управления на основе стоимости для стейкхолдеров

Ядро Іи STVM является пространство интересов как финансовых, так и нефинансовых стейкхолдеров, которое превращается в объект структурирования. Их оценивание и балансирование - это неотъемлемое условие анализа и выбора стратегических альтернатив. Балансирование множественных интересов означает, что платформа создания стоимости формируется тремя видами капиталов: финансовым (ФК), интеллектуальным (ИК) и социальным (СК). Последние два формируют системный контур нефинансовых форм капитала, основанный на создании и накоплении специфических активов, которые либо невозможно воспроизвести, либо это требует значительных издержек и времени. Достижение оптимального соотношения финансового, интеллектуального и социального капиталов рассматривается в качестве необходимого условия создания стоимости для всех стейкхолдеров (STV). В движении к этой цели необходимо учитывать прямые и обратные связи между интересами стейкхолдеров и управленческими решениями и практиками.

Модель управления на основе стоимости для стейкхолдеров (STVM) как элемент системы интегрированного управления стоимостью компании обладает существенными отличиями от управления на основе стоимости акционерного капитала (VBM). Во-первых, она базируется на задаче приращения стоимости для стейкхолдеров (stakeholder value added, 
STVA). Ее решение не идентично максимизации стоимости акционерного капитала, поскольку требуемые для их совпадения предпосылки в реальных экономических условиях не выполняются. Задача, возникающая в модели STVM, означает трансформацию функции максимизации в многокритериальную задачу оптимизации.

Во-вторых, модель STVM исходит из нового стоимостного мышления, предполагающего объединение двух контуров интересов - финансовых и нефинансовых стейкхолдеров. Балансирование в пространстве интересов основано на принципе формирования платформы создания стоимости тремя видами капиталов: финансовым, интеллектуальным и социальным. Достижение положительной экономической прибыли для нефинансовых стейкхолдеров может требовать решений, при которых экономическая прибыль для финансовых стейкхолдеров может не расти или даже оказаться отрицательной величиной. Существенные конфликты могут возникать между стейкхолдерами, ориентированными на краткосрочные и, напротив, долгосрочные интересы. Балансирование интересов предполагает их согласование путем формирования в стратегическом процессе компании процедур, позволяющих добиться состоянии гармонизации и при принятии решений, и в их реализации.

Третье отличие состоит во введении в модель STVM нового, специфического контура нефинансовых форм капитала (интеллектуального и социального). Это означает не просто расширение границ охвата, а новые подходы к анализу и выбору стратегических альтернатив компании. Два контура управления стоимостью предполагают применение дополнительных инструментов для оценки результатов создания стоимости и исполнения стратегий. Поэтому нужна инструментальная составляющая модели STVM для осуществления таких оценок. На уровне создания стоимости необходимо новое стоимостное мышление, ориентированное на приращение стоимости для финансовых и нефинансовых стейкхолдеров и соответствующее задаче перехода к инновационной экономике. Оно формирует рамки для развития финансового анализа компании и для структурирования пространства интересов стейкхолдеров. Создание ценности для клиентов и выявление рыночных возможностей как процесса, обеспечивающего производство продуктов (услуг), формирующих конкурентные преимущества компании, составляют лишь части процесса создания ее стоимости. Анализ, выявление стратегических намерений стейкхолдеров, идентификация противоречий или конфликтов интересов и намерений, разработка мер гармонизации интересов неотъемлемые элементы процесса создания стоимости по критериям STVA. Формирование системного контура нефинансового капитала обусловливает необходимость построения сбалансированной архитектуры капитала и гармонизацию интересов стратегических финансовых и нефинансовых стейкхолдеров.

Таким образом, новое стоимостное мышление создает оболочку для совокупности процессов координации в компании, образующих всю систему интегрированного управления стоимостью. Стержень подхода вытекает из концепции гармоничной компании, предопределяющей задачи и методы балансирования интересов стейкхолдеров, которые в свою очередь обеспечиваются инструментальной составляющей. $\mathrm{B} \quad$ рамках модели управления на основе стоимости для стейкхолдеров (STVM) такая инструментальная составляющая, требуемая для воплощения концепции гармоничной компании, охватывает совокупность процессов стратегического планирования в компании на основе критерия стоимости для стейкхолдеров, инструменты текущей оценки ее создания, которые также применяются для разработки методов вознаграждения за создание стоимости для стейкхолдеров. Существенной характеристикой инструментальной составляющей становится способность разрабатываемых методов и показателей обеспечивать интеграцию двух контуров капитала в обоснованиях выбора стратегических альтернатив и оценке их реализации.

В целях вовлечения системного контура нефинансового капитала и интеграции интересов финансовых и нефинансовых стейкхолдеров необходимы изменения в корпоративном управлении компании и в деятельности советов директоров. Достижение 
прироста стоимости для стейкхолдеров (STVA) - существенно более сложная задача, требующая адекватной перестройки деятельности советов директоров. Поэтому вторым элементом системы интегрированного управления стоимостью становится новая модель корпоративного управления на основе стоимости для всех стейкхолдеров (stakeholder's value based corporate governance, STVG). Таким образом, в системе интегрированного управления стоимостью компании формируется контур совета директоров с зонами его стратегической ответственности. Суммируем ключевые отличия модели STVG, показанной на рисунке 3 (Ивашковская, 2010).

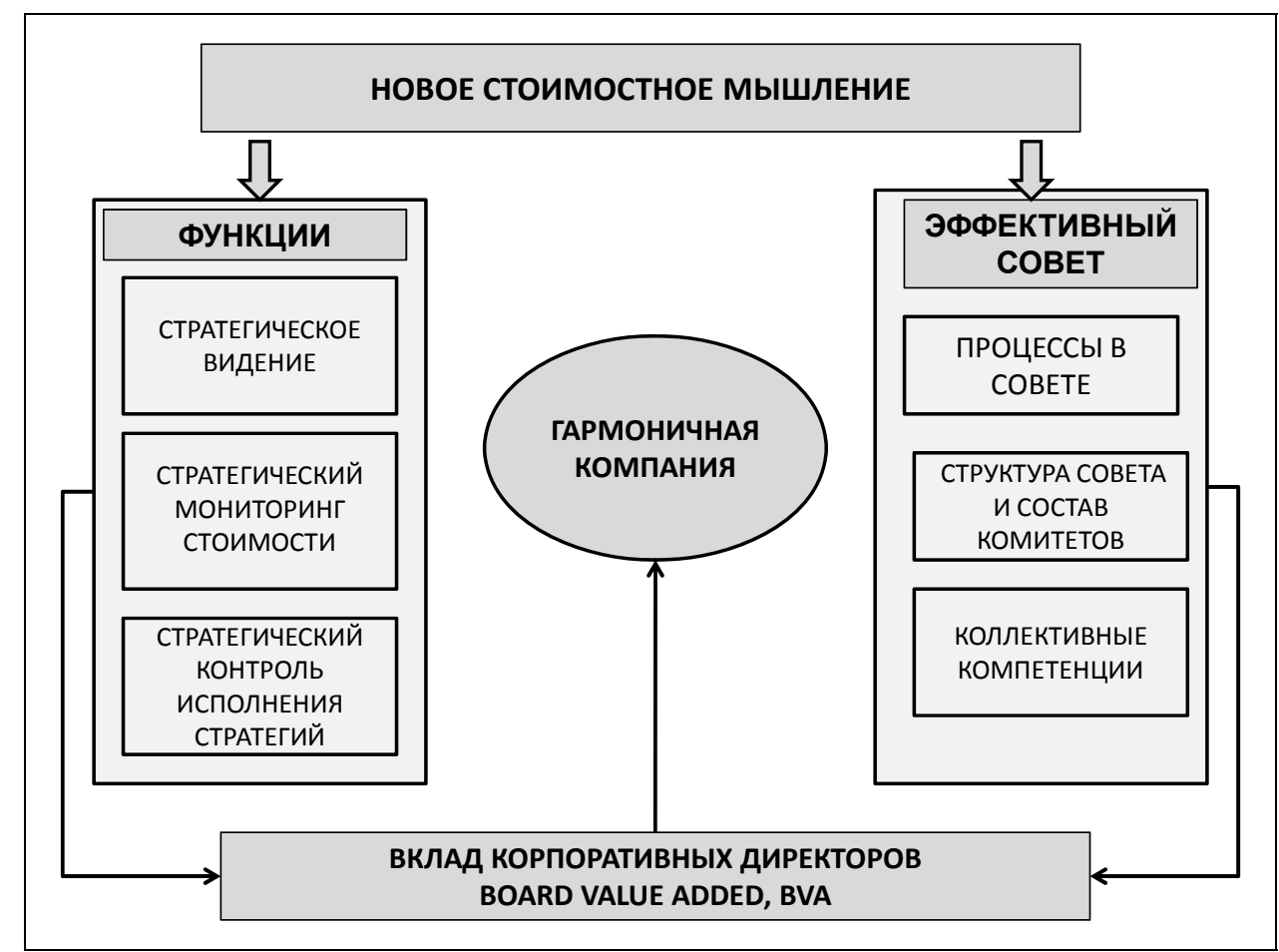

Рисунок 3. Модель корпоративного управления на основе стоимости для стейкхолдеров

Первое существенное свойство состоит в том, что предлагаемая нами модель основана на стратегически ориентированной системе корпоративного управления (Ивашковская, 2009). Такая система приходит на смену преобладающей сейчас сбалансированной системе корпоративного управления, нацеленной на достижение баланса интересов между менеджментом и собственниками и интересов среди собственников за счет построения структуры органов корпоративного управления, состава совета директоров и процедур его работы. Создание стратегически ориентированной системы корпоративного управления, вопервых, предполагает сдвиг от реактивного поведения совета директоров при возникновении проблем в реализации стратегии и проявляющихся ошибках к проактивному поведению совета, нацеленному на их предупреждение. В ней предусмотрены механизмы коррекции стратегических решений, заложенные в сам процесс разработки и выбора советом директоров стратегических альтернатив для компании. Во-вторых, стратегически ориентированная система корпоративного управления обеспечивает смещение акцентов от структуры и состава совета директоров к процессам в их деятельности и к формированию эффективных советов директоров.Корпоративные директора должны эффективно выполнять обе функции: с одной стороны, мониторинга исполнения стратегических решений, с другой - их разработки и улучшения.

Второе существенное свойство модели корпоративного управления на основе создания стоимости стейкхолдеров (STVG) состоит в том, что задачей совета директоров становится построение гармоничной компании (Ивашковская, 2011). Иерархия интересов по линии агент-принципал создает ограничения в трактовке создания стоимости компании в условиях перехода к инновационной экономике. С этим связано снижение роли агентского конфликта 
между интересами акционеров (в роли принципала) и наемного менеджмента (в роли исполнителя-агента) как парадигмы анализа компании. При решении задачи максимизации стоимости для финансовых стейкхолдеров-акционеров учет возможных экстерналий, означающих не предусмотренные контрактом последствия для интересов остальных стейкхолдеров, не является предпосылкой принятия решений. Учет таких эффектов осуществляется после принятия решения, рассматриваемого как инструмент достижения цели максимизации стоимости акционерного капитала. Баланс интересов в гармоничной компании, напротив, предполагает обратную последовательность: структурирование более широкого пространства интересов, их анализ, выявление экстерналий и их учет в процессе разработки самого решения. Таким образом, вовлечение последствий разрабатываемого решения для интересов остальных категорий стейкхолдеров должно осуществляться до, а не после его принятия. Существенное отличие в структурировании и балансировании интересов в гармоничной компании связано не только с моментом вовлечения оценивания последствий (экстерналий) в принятие решений, а с характером самих экстерналий. Балансирование интересов в гармоничной компании основано на учете всех типов экстерналий, как негативных, так и позитивных.

Поэтому в предлагаемой модели корпоративного управления (STVG) стратегические роли совета директоров приобретают дополнительную специфику. Новое стоимостное мышление предполагает понимание необходимости баланса между всеми формами капитала - финансовым и новым, нефинансовым контуром (социальным и интеллектуальным капиталами). Совету директоров необходимы нестандартные действия для обеспечения долгосрочного приращения стоимости. Создание приращения стоимости для нефинансовых стейкхолдеров может требовать решений, при которых экономическая прибыль для финансовых стейкхолдеров может не увеличиться в краткосрочной перспективе.

Задача построения гармоничной компании предполагает ответственность совета директоров за выработку ясных представлений об ограничениях, допустимых для процессов создания стоимости, в рамках которых должен действовать менеджмент, формирование системы ограничений и контроль за их соблюдением. Поэтому в предлагаемой модели STVG советы директоров должны взять на вооружение новую задачу: опираться на принцип «неубывания» стоимости как важнейший ограничитель в принятии решений. Если формализовать эту задачу, то ее можно выразить в виде производной от стоимости компании (V). Для любого момента времени t:

$\mathrm{dV} / \mathrm{dt} \geq 0$.

Таким образом, на уровне корпоративного управления, а не менеджмента, задача создания стоимости сводится $\kappa$ формированию советами директоров ограничения неубывания стоимости для стейкхолдеров. Такая система ограничений должна выполнять несколько взаимосвязанных задач. Во-первых, ограничивать возможности принятия «близоруких» решений менеджментом. Риск «близорукости» в традиционном понимании, основанном на задаче максимизации стоимости акционерного капитала, обычно связывают с ситуациями в состоянии финансового рынка, когда его участники не могут идентифицировать подлинные факторы создания прироста рыночной стоимости, происходит ли он из фундаментальных факторов или вызван иными (например, сигнальными, манипулятивными) процессами. В рамках стейкхолдерской парадигмы создания стоимости «близорукие» решения связаны с перераспределением потоков выгод в адрес собственников в ущерб потокам, создаваемым ключевыми стейкхолдерами. Во-вторых, система ограничений, формируемая советом директоров, призвана влиять на издержки выхода стейкхолдеров из бизнеса, которые понесут конкретные категории нефинансовых стейкхолдеров в случае решения о прерывании отношений из-за снижения выгод, получаемых из компании. В-третьих, следуя новому стоимостному мышлению, советы директоров должны выстраивать меры увеличения издержек выхода из бизнеса данной компании для ключевых стейкхолдеров. Поэтому система ограничений предполагает одновременно сохранение интеллектуального и социального капиталов, носителями которых 
являются стейкхолдеры компании, а также создание стимулов для стейкхолдеров сохранить отношения с компанией.

Как показано на рисунке 1, третий элемент системы интегрированного управления стоимостью компании - это модель стратегического отчета о стоимости для мониторинга стоимости для всех стейкхолдеров. Она предусматривает совокупность инструментов выявления изменений в стоимости для стейкхолдеров, соблюдения либо нарушения ограничений, установленных советами директоров как рамок процесса создания стоимости для стейкхолдеров. Новые финансовые данные и нефинансовые индикаторы должны образовать дополнительные специальные блоки информации о компании - стратегический отчет о стоимости (Ивашковская, 2008б). В моделировании стоимости для всех стейкхолдеров, в выборе критериев, показателей и индикаторов директора должны быть независимыми от менеджмента. Новые роли совета директоров, показанные выше, формируют новую культуру стоимостного мышления в компании и, по существу, форматируют компанию под решение задач накопления в ней интеллектуального и социального капитала.

Совокупность отчетов, формирующих стратегический отчет о стоимости компании, представлена на рисунке 4.

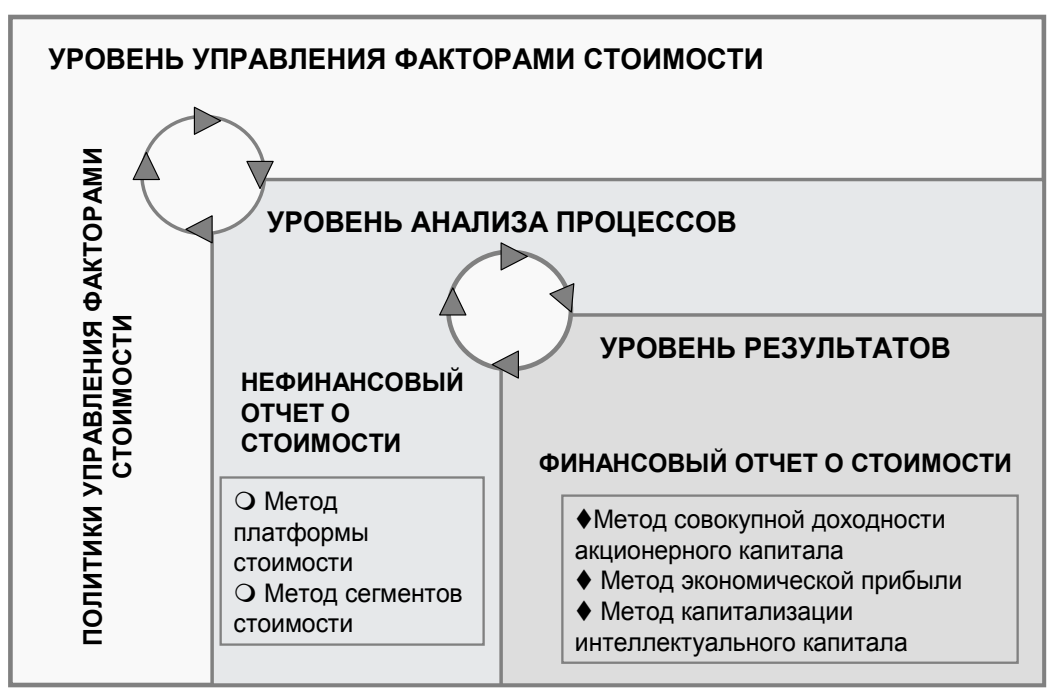

Рисунок 4. Модель стратегического отчета о стоимости компании

Для оценивания результатов прежде всего нужны дополнительные финансовые отчеты, например подготовленные методом экономической прибыли и отражающие соотношение бухгалтерской прибыли и затрат на капитал (требуемого дохода за риск). Возможные структуры новых финансовых отчетов рассмотрены автором в предыдущих работах (Ивашковская, 2008б; Ивашковская, 2009). Нефинансовые отчеты о стоимости можно строить как путем систематизации совокупности разнообразных данных, характеризующих дерево факторов стоимости как целое, так и путем концентрации данных об отдельных, ключевых факторах, определяющих тенденцию изменения стоимости для стейкхолдеров в перспективе. Первый путь можно условно назвать методом платформы наращения стоимости. Метод платформы наращения стоимости предполагает, что нефинансовый отчет охватывает как стратегические и операционные факторы стоимости, так и подытоживает результаты в построении устойчивых отношений со стейкхолдерами. Поэтому в него вовлекаются показатели и индикаторы, отражающие качество этих отношений. Особенность такого подхода и в том, что он ориентирован на освещение среднесрочных тенденций в развитии компании. Поэтому особое внимание уделяется информации, составляющей целостную «платформу» стоимости. Одним из примеров воплощения такого метода в реальной практике является формат «Отчета о стоимости», или Value reporting ${ }^{\mathrm{TM}}$, разрабатываемый консультантами компании PriceWaterhouseCoopers (The Value Reporting 
Revolution, 2001; DiPiazza, Eccles, 2002) в качестве дополнений к годовой отчетности и применяемый многими ее клиентами. Ее вариант представляет собой самостоятельный публичный и аудируемый нефинансовый отчет, состоящий из двух разделов: о внешних процессах в конкуренции на рынках сбыта и о внутренних инструментах создания стоимости. Согласно этой концепции, отчет о стоимости должен состоять из четырех блоков информации, объединенных в разделы о внутренних факторах создания стоимости и внешних процессах. К внешним процессам в данной модели отнесены условия конкуренции на рынках сбыта, государственное регулирование отрасли, макроэкономические тенденции и тенденции развития отрасли. Внутренние факторы охватывают три подраздела: стратегия и структура, политики управления стоимостью, результаты деятельности. Для многопрофильных компаний соответствующие факторы должны рассматриваться не только на корпоративном уровне, но и в разрезе направлений бизнеса.

Альтернативный путь построения нефинансового отчета о стоимости в модели стратегического отчета о стоимости для стейкхолдеров - это метод сегментов стоимости. Под сегментом стоимости в данном случае имеется в виду обобщенная, двусторонняя оценка добавленной стоимости применительно к конкретному виду стратегических стейкхолдеров. Двусторонний характер оценивания всего процесса создания стоимости для стейкхолдеров и его результатов означает, с одной стороны, вклад в стоимость компании, созданный конкретными видами стейкхолдеров, и с другой - вклад для них, созданный в компании (Ивашковская, 2008б).

\section{Список литературы}

1. Ивашковская И.В. Модель стратегического стоимостного анализа фирмы // Экономическая наука современной России. 2008а. № 3. С. 115-127.

2. Ивашковская И.В. Стратегический мониторинг создания стоимости для всех стейкхолдеров компании // Вестник Финансовой академии. 2008б. № 3.

3. Ивашковская И.В. Финансовые измерения корпоративных стратегий // Аудит и финансовый анализ. 2007. № 5. С. 150-163.

4. Ивашковская И.В. Финансовые измерения корпоративных стратегий. Стейкхолдерский подход. М.: ИНФРА-М, 2008в.

5. Ивашковская И.В. Моделирование стоимости компании. Стратегическая ответственность советов директоров. М.: ИНФРА-М, 2009.

6. Ивашковская И.В. Модель корпоративного управления на основе стоимости для стейкхолдеров // Вестник Финансовой академии. 2010. № 2(56). С. 29-35.

7. Ивашковская И.В. Развитие стейкхолдерского подхода в методологии финансового анализа: гармоничная компания // Корпоративные финансы. 2011. № 3(19). С. 59-70. [Электронный ресурс]. http://ecsocman.hse.ru/hsedata/2011/11/07/1272283128/CFJ19_59_70.

8. Castanias, R., Helfat, C.E. (1991), Managerial Resources and Rents, Journal of Management, 1(19) (1991) 155-171.

9. Castanias, R.P., Helfat, C.E. (2001),The Managerial Rents Model: Theory and Empirical Analysis, Journal of Management, 6(27) (2001) 661-678.

10. Charreaux, G., Desbrieres, P. (2001), Corporate Governance: Stakeholder Value Versus Shareholder Value, Journal of Management and Governance, 5 (2001) 107.

11. DiPiazza, S.J., Eccles, R.G. (2002), Building Public Trust: The Future of Corporate Reporting. John Wiley \& Sons, Inc..

12. Milgrom, P., Roberts, J. (1992), Economics, Organization and Management. Prentice Hall.

13. The Value Reporting Revolution. Moving Beyond the Earnings Game(2001), Eccles R.G., Herz R.H., Keegan E.M., Philipps D.M.H. John Wiley \& Sons, Inc. 